\title{
Grape seed extract attenuates arsenic-induced nephrotoxicity in rats
}

\author{
JIANGONG ZHANG ${ }^{1,2^{*}}$, XINJUAN PAN ${ }^{3 *},{\text { NING } \mathrm{LI}^{3,4^{*}}, \mathrm{XING} \mathrm{LI}^{3}, \text { YONGCHAO WANG }}^{3}$, \\ XIAOZHUAN LIU ${ }^{3}$, XINJUAN YIN ${ }^{3}$ and ZENGLI YU ${ }^{3}$ \\ ${ }^{1}$ Affiliated Cancer Hospital of Zhengzhou University, Zhengzhou, Henan 450008; ${ }^{2}$ Henan Cancer Hospital, Zhengzhou, \\ Henan 450008; ${ }^{3}$ School of Public Health, Zhengzhou University, Zhengzhou, Henan 450001; \\ ${ }^{4}$ College of Food Science and Technology, Henan Agriculture University, Zhengzhou, Henan 450002, P.R. China
}

Received July 1, 2013; Accepted October 24, 2013

DOI: $10.3892 /$ etm.2013.1381

\begin{abstract}
Oxidative stress is a recognized factor in nephrotoxicity induced by chronic exposure to inorganic arsenic (As). Grape seed extract (GSE) possesses antioxidant properties. The present study was designed to evaluate the beneficial effects of GSE against arsenic-induced renal injury. Healthy, male Sprague-Dawley rats were exposed to As in drinking water (30 ppm) with or without GSE (100 mg/kg) for 12 months. The serum proinflammatory cytokine levels and mRNA expression levels of fibrogenic markers in the renal tissues were evaluated using enzyme-linked immunosorbent assay and quantitative polymerase chain reaction, respectively. The protein expression levels of nicotinamide adenine dinucleotide phosphate (NADPH) subunits, transforming growth factor- $\beta 1$ (TGF- $\beta 1)$ and phosphorylated Smad2/3 (pSmad2/3) were assessed using western blot analysis. The results demonstrated that cotreatment with GSE significantly improved renal function, as demonstrated by the reductions in relative kidney weight (\% of body weight) and blood urea nitrogen, and the increase in the creatinine clearance capacity. GSE attenuated the As-induced changes in the serum levels of tumor necrosis factor- $\alpha$ (TNF- $\alpha$ ), interleukin-6 (IL-6) and IL-1 $\beta$ and the mRNA levels of TGF- $\beta 1, \alpha$-smooth muscle actin ( $\alpha$-SMA),
\end{abstract}

Correspondence to: Professor Zengli Yu, School of Public Health, Zhengzhou University, 100 Science Road, Zhengzhou, Henan 450001, P.R. China

E-mail: zly@zzu.edu.cn

*Contributed equally

Abbreviations: NADPH, nicotinamide adenine dinucleotide phosphate; BUN, blood urea nitrogen; $\mathrm{C}_{\mathrm{Cr}}$, creatinine clearance; $\mathrm{P}_{\mathrm{Cr}}$, plasma creatinine; $\alpha$-SMA, $\alpha$-smooth muscle actin; FN, fibronectin; CTGF, connective tissue growth factor; GSE, grape seed extract; ROS, reactive oxygen species; Nox, NADPH oxidase; PCs, protein carbonyls; TBARS, thiobarbituric acid reactive substances

Key words: grape seed extract, chronic arsenic exposure; nephrotoxicity, oxidative stress, NADPH oxidase, TGF- $\beta / \mathrm{Smad}$ connective tissue growth factor (CTGF) and fibronectin (FN) in renal tissue. Furthermore, administration of GSE markedly reduced As-stimulated reactive oxygen species (ROS) production and Nox activity, as well as the protein expression levels of the NADPH subunits (Nox2, p47phox and Nox4). In addition, GSE cotreatment was correlated with a significant reduction in TGF- $\beta /$ Smad signaling, as demonstrated by the decreased protein levels of TGF- $\beta 1$ and $\mathrm{pSmad} 2 / 3$ in renal tissue. This study indicated that GSE may be a useful agent for the prevention of nephrotoxicity induced by chronic exposure to As. GSE may exert its effects through the suppression of Nox and inhibition of TGF- $\beta /$ Smad signaling activation.

\section{Introduction}

Arsenic (As) is a naturally occurring element that is ubiquitously present in the environment. Chronic exposure to inorganic As has been indicated to be correlated with chronic changes in a number of organs, including the liver, kidney, skin and bladder. The kidney, as the primary organ for the excretion of metabolites, appears to be one of the main targets of As (1). The toxicity of As in the kidney has been demonstrated in the human population and animals through renal pathology and functional changes (2-4). In addition, the mechanisms of As-induced kidney damage have been investigated in numerous studies (5). Among the suggested mechanisms, oxidative stress is one of the best-accepted theories (6-8). It has been indicated that As is capable of increasing the generation of reactive oxygen species (ROS), such as intracellular peroxide, superoxide anion radical $\left(\mathrm{O}_{2}{ }^{\circ}\right)$, hydrogen peroxide $\left(\mathrm{H}_{2} \mathrm{O}_{2}\right)$ and hydroxyl free radicals $\left(\mathrm{OH}^{\circ}\right)$, which stimulate proinflammatory and profibrogenic cytokines (9) and are able to directly or indirectly damage cellular DNA and protein (7). Therefore, ROS are a significant causal factor in As-induced renal nephrotoxicity and fibrosis.

Transforming growth factor- $\beta 1$ (TGF- $\beta 1$ ) is a potent profibrogenic cytokine, and elevated TGF- $\beta 1$ levels are causatively involved in the activation of profibrotic signaling pathways initiated by oxidative stress (10). The TGF- $\beta$ signaling pathway is regulated predominantly by Smads. TGF- $\beta$-activated Smad pathways are pivotal for the induction of extracellular matrix (ECM) generation, myofibroblast differ- 
entiation, epithelial-mesenchymal transformation (EMT) and disease progression (11-14). Having reviewed the mechanisms of As-induced renal nephrotoxicity and fibrosis, we hypothesized that scavenging ROS, reducing oxidative stress and/or inhibiting the activities of proinflammatory and profibrogenic cytokines may partially reduce As-induced nephrotoxicity. Grape seed extract (GSE), which is rich in polyphenols, has been demonstrated to possess potent antioxidant properties and is considered to be a safe and effective antioxidant compound. It has been shown that the antioxidant activity of GSE is greater than that of vitamins $\mathrm{C}$ and $\mathrm{E}$ and $\beta$-carotene (15). GSE may exert its antioxidant and anti-inflammatory effects (16) by scavenging oxygen free radicals, inhibiting lipid peroxidation and the formation of inflammatory cytokines, altering cell membrane receptors and intracellular signaling pathway proteins, and modulating gene expression (17). In a previous study, we demonstrated that GSE may inhibit As-induced rat liver injury (18).

The initial aim of the present study was to elucidate whether dietary supplementation with GSE was capable of inhibiting chronic As-induced renal injury and fibrosis. A further aim was to explore the molecular mechanisms implicated in the action of GSE by measuring the effects of GSE treatment on nicotinamide adenine dinucleotide phosphate (NADPH) oxidase (Nox) activity and the TGF- $\beta$ signaling pathway. In this study, rats received a life-long, non-lethal dosage of inorganic sodium arsenite $\left(\mathrm{NaAsO}_{2}, \mathrm{As} ; 30 \mathrm{ppm}\right.$ in drinking water) for 12 months, with or without the co-administration of GSE and the effects on oxidative stress and TGF- $\beta / \mathrm{Smad}$ signaling were evaluated.

\section{Materials and methods}

Chemicals and animal treatments. The As used in the study was purchased from Sigma (St. Louis, MO, USA). GSE, containing monomeric catechins, dimeric and trimeric procyanidins, and larger procyanidins (Table I), was obtained from Jianfeng, Inc. (Lot no. G050412; Tianjin, China).

All animal procedures were performed in accordance with the Animal Care and Use Committee of Zhengzhou University (Zhengzhou, China). The experimental protocols were approved by the Animal Care and Use Committee of Zhengzhou University. The study used healthy, male Sprague-Dawley rats

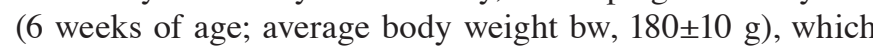
were randomly divided into four groups (Groups 1-4). The rats in each group (10 rats per group) were treated as follows: Group 1 received only drinking water; Group 2 received As in the drinking water at a concentration of $30 \mathrm{ppm}$; Group 3 received $100 \mathrm{mg} / \mathrm{kg}$ GSE, which was dissolved in the drinking water, every other day by oral gavage; and Group 4 received As plus GSE, with dosages and treatments as mentioned for Groups 2 and 3, respectively. The animals were housed in groups of three rats per cage at $22^{\circ} \mathrm{C}$ with a 12 -h light/dark cycle and were given free access to food and water. The food and water intake, as well as the body weight of the animals, were monitored throughout the 12-month experimental period.

Blood collection and tissue preparation. At the end of experiment, the rats were placed in individual metabolic cages for a 24-h urine collection. To eliminate contamination
Table I. Composition of grape seed extract (GSE).

\begin{tabular}{lc}
\hline Compounds & $\%(w t / w t)$ \\
\hline Monomers & $3.7-3.9$ \\
Catechin & $1.3-1.9$ \\
Epicatechin & $1.4-2.0$ \\
Epicatechin gallate & $1.0-1.7$ \\
Dimers + trimers & $28-31$ \\
Procyanidin B1 & $6.8-7.4$ \\
Procyanidin B2 & 4.9 \\
Procyanidin B3 & $3.2-3.7$ \\
Procyanidin B4 & 2.1 \\
Total procyanidins & $>96$ \\
\hline
\end{tabular}

Composition values based on the Vitaflavan specification (Vitaflavan French grape seed extract: polyphenols $>96 \%$ ) and Lot Certificates of Analysis provided by the supplier (Jianfeng, Inc., Tianjin, China).

of the urine samples, the rats received only water during the collection period. Following the urine collection, the animals were immediately anesthetized with ether and the blood was collected using cardiac puncture. The blood was allowed to clot and was subsequently centrifuged and stored at $-80^{\circ} \mathrm{C}$ for analysis. The renal tissues were collected and used for protein extraction or total RNA isolation, as well as for the analysis of ROS production or Nox activity. The protein concentrations were assessed using a protein assay kit (Bio-Rad, Hercules, CA, USA) and bovine serum albumin was used as a standard.

Renal function parameters. Blood urea nitrogen (BUN), urinary protein (Up) levels, plasma creatinine $\left(\mathrm{P}_{\mathrm{Cr}}\right)$ and creatinine clearance $\left(\mathrm{C}_{\mathrm{Cr}}\right)$ were measured using commercial assay kits, in accordance with the manufacturer's instructions (Bioassay Systems LLC, Hayward, CA, USA).

Oxidative damage analysis. ROS production in the renal tissues was determined using a 2',7'-dichlorofluorescin diacetate (DCF-DA; Invitrogen Life Technologies, Carlsbad, CA, USA) assay, where DCF-DA was converted into highly fluorescent DCF by cellular peroxides (including $\mathrm{H}_{2} \mathrm{O}_{2}$ ), as previously described (19). Nox activity in the cell membranes and cytosolic fractions was measured through the detection of ROS production using a lucigenin-derived chemiluminescence assay with NADPH as the substrate, as previously described (20). Protein carbonyls (PCs) were analyzed using the 2,4-dinitrophenylhydrazine (DNPH) method, as previously described (21). Lipid peroxidation was assessed using a thiobarbituric acid reactive substances (TBARS) assay (22). All the chemicals used were analytic grade and purchased from Sigma.

Levels of proinflammatory cytokines. Serum levels of tumor necrosis factor- $\alpha$ (TNF- $\alpha$ ), interleukin-6 (IL-6) and IL-1 $\beta$ were quantified using Quantikine enzyme-linked immunosorbent assay (ELISA) kits for TNF- $\alpha$, rat IL-6 and rat IL-1 $\beta$ (R\&D Systems, Minneapolis, MN, USA), respectively, in accordance with the manufacturer's instructions. 
Table II. Primer sequences for quantitative polymerase chain reaction.

\begin{tabular}{lll}
\hline Gene & \multicolumn{1}{c}{ Forward } & \multicolumn{1}{c}{ Reverse } \\
\hline TGF- $\beta 1$ & 5'-ATACGCCTGAGTGGCTGTCT-3' & 5'-TGGGACTGATCCCATTGATT-3' \\
$\alpha-S M A$ & 5'-CCGAGATCTCACCGACTACC-3' & 5'-TCCAGAGCGACATAGCACAG-3' \\
FN & 5'-TGCAATGATCAGGACACCAGG-3 & 5'-GTAATTCCGGTTGCTGTACAG-3' \\
CTGF & 5'-GAGCTTTCTGGCTGCACC-3' & 5'-TCTCCGTACATCTTCCTG-3' \\
$\beta$-actin & 5'-CCATTGAACACGGCATTGTC-3' & 5'-TCATAGATGGGCACACAGTG-3'
\end{tabular}

TGF- $\beta 1$, transforming growth factor- $\beta 1 ; \alpha$-SMA, $\alpha$-smooth muscle actin; FN, fibronectin; CTGF, connective tissue growth factor.

Table III. GSE improves As-induced renal injury.

\begin{tabular}{lcccc}
\hline Parameter & Control group & GSE group & As group & GSE + As group \\
\hline $\mathrm{BW}(\mathrm{g})$ & $571.4 \pm 30.1$ & $582.9 \pm 39.1$ & $411.3 \pm 19.2^{\mathrm{a}}$ & $589.3 \pm 29.7^{\mathrm{b}}$ \\
$\mathrm{KW}(\mathrm{g})$ & $4.19 \pm 0.69$ & $4.23 \pm 1.01$ & $5.01 \pm 0.87$ & $4.55 \pm 0.99$ \\
$\mathrm{KW} / \mathrm{BW}(\mathrm{g} / \mathrm{kg})$ & $7.33 \pm 1.6$ & $7.26 \pm 1.2$ & $12.10 \pm 1.7^{\mathrm{a}}$ & $7.72 \pm 1.5^{\mathrm{b}}$ \\
$\mathrm{Up}(\mathrm{mg} / \mathrm{day} / 100 \mathrm{~g} \mathrm{BW})$ & $20.1 \pm 1.6$ & $18.3 \pm 2.4$ & $45.3 \pm 9.1^{\mathrm{a}}$ & $29.6 \pm 7.3^{\mathrm{ba}}$ \\
$\mathrm{P}_{\mathrm{Cr}}(\mathrm{mg} / \mathrm{dl})$ & $0.68 \pm 0.09$ & $0.67 \pm 0.08$ & $1.90 \pm 0.15^{\mathrm{a}}$ & $1.10 \pm 0.11^{\mathrm{b}}$ \\
$\mathrm{BUN}(\mathrm{mg} / \mathrm{dl})$ & $31.1 \pm 4.6$ & $30.8 \pm 4.9$ & $58.9 \pm 11.2^{\mathrm{a}}$ & $40.1 \pm 9.7^{\mathrm{b}}$ \\
$\mathrm{C}_{\mathrm{Cr}}(\mathrm{ml} / \mathrm{min})$ & $4.8 \pm 0.7$ & $4.9 \pm 0.9$ & $2.9 \pm 0.1^{\mathrm{a}}$ & $3.9 \pm 0.4^{\mathrm{b}}$ \\
\hline
\end{tabular}

Results are presented as the mean \pm standard deviation $(\mathrm{n}=10)$. ${ }^{a}$ Values differ significantly from those of control rats $(\mathrm{P}<0.01)$; ${ }^{b} \mathrm{values}$ differ significantly from those of arsenic (As)-treated rats $(\mathrm{P}<0.01)$. GSE, grape seed extract; BW, body weight; KW, kidney weight; Up, urinary protein; $\mathrm{P}_{\mathrm{Cr}}$, plasma creatinine, $\mathrm{C}_{\mathrm{Cr}}$, creatinine clearance; $\mathrm{BUN}$, blood urea nitrogen.

Quantitative polymerase chain reaction ( $q P C R$ ). Total RNA was extracted from the kidney tissue using TRIzol ${ }^{\circledR}$ reagent (Gibco, Grand Island, NY, USA). cDNA was transcribed from $2 \mu \mathrm{g}$ RNA using a high-capacity cDNA reverse transcription kit (Applied Biosystems, Foster City, CA, USA), in accordance with the manufacturer's instructions. The target genes were amplified using Power SYBR ${ }^{\circledR}$ Green PCR Master Mix reagent (Applied Biosystems). The amplification was performed in a Real-Time PCR system (Applied Biosystems 7500 systems; Applied Biosystems) and modified PCR cycles were used, as follows: Initial denaturation at $95^{\circ} \mathrm{C}$ for $2 \mathrm{~min}$, followed by 35 cycles at $95^{\circ} \mathrm{C}$ for $30 \mathrm{sec}$ and $60^{\circ} \mathrm{C}$ for $30 \mathrm{sec}$. The housekeeping gene $\beta$-actin was used as an internal control, and gene-specific mRNA expression was normalized against $\beta$-actin expression. Relative quantification using the $2^{-\Delta \Delta \mathrm{CT}}$ method was performed by comparisons with the control group. The primer sequences are summarized in Table II.

Western blot analysis. Aliquots of the renal tissues were homogenized in ice-cold lysis buffer [1\% NP-40; $10 \%$ glycerol; 20 mM Tris-Cl, pH 7.5; 150 mM NaCl; 1 mM EDTA; 1 mM ethylene glycol-O,O'-bis(2-aminoethyl)-N,N,N',N-tetraacetic acid (EGTA), $1 \mathrm{mM} \mathrm{NaVO}_{4}, 10 \mathrm{mM} \mathrm{NaPO}_{4}, 10 \mu \mathrm{g} / \mathrm{ml}$ leupeptin and $1 \mathrm{mM}$ phenylmethylsulfonyl fluoride (PMSF)]. Total protein (30-50 $\mu \mathrm{g}$ ) was subjected to $12 \%$ SDS-PAGE, transferred to nitrocellulose membranes and incubated with primary antibodies against p47phox (sc-14015), Nox2 (sc-27635), Nox4 (sc-30141), $\beta$-actin (sc-8432), TGF- $\beta 1$ (sc-146; all from Santa
Cruz Biotechnology, Inc., Santa Cruz, CA, USA), phosphorylated Smad3 (pSmad3; cat. no. 9514) or pSmad2 (cat. no. 3101; both from Cell Signaling Technology, Inc., Danvers, MA, USA) overnight at $4^{\circ} \mathrm{C}$. The membranes were subsequently probed with horseradish peroxidase-coupled secondary antibodies (Santa Cruz Biotechnology, Inc.) at room temperature for $1 \mathrm{~h}$, prior to being washed again and visualized using an enhanced chemiluminescence reaction (Amersham ECL ${ }^{\mathrm{TM}}$ Western Blotting System; Amersham, Piscataway, NJ, USA). The protein expression was quantified densitometrically using LabWorks 4.5 software of American UVP Bioimaging System (Upland, CA, USA), and changes in expression were normalized to the internal standard, $\beta$-actin.

Statistical analysis. The grouped data were evaluated using SPSS 13.0 statistical software (SPSS, Inc., Chicago, IL, USA). The methods used to test the hypothesis included one-way analysis of variance (ANOVA), followed by the Least Significant Difference (LSD) test. A value of $\mathrm{P}<0.05$ was considered to indicate a statistically significant difference. The results are expressed as the mean \pm standard deviation.

\section{Results}

GSE improves As-induced nephrotoxicity. No rats died during the 12-month experimental period. No significant differences were observed in the food and water consumption among the four groups of animals. However, As-treated rats had lower 
Table IV. Serum proinflammatory cytokine levels in different treatment groups.

\begin{tabular}{lcccc}
\hline Cytokine & Control group & GSE group & As group & GSE + As group \\
\hline IL-1 $\beta(\mathrm{pg} / \mathrm{ml})$ & $17.1 \pm 6.1$ & $15.3 \pm 5.7$ & $58.3 \pm 17.1^{\mathrm{a}}$ & $22.9 \pm 7.2^{\mathrm{b}}$ \\
IL-6 $(\mathrm{pg} / \mathrm{ml})$ & $33.5 \pm 9.6$ & $34.1 \pm 6.5$ & $73.2 \pm 10.1^{\mathrm{a}}$ & $38.9 \pm 8.8^{\mathrm{b}}$ \\
TNF- $\alpha(\mathrm{pg} / \mathrm{ml})$ & $13.9 \pm 3.3$ & $11.9 \pm 2.3$ & $37.7 \pm 10.1^{\mathrm{a}}$ & $16.4 \pm 9.1^{\mathrm{b}}$
\end{tabular}

Results are presented as the mean \pm standard deviation $(\mathrm{n}=10)$. ${ }^{a}$ Values differ significantly from those of control rats $(\mathrm{P}<0.01)$; ${ }^{\mathrm{b}} \mathrm{values}$ differ significantly from those of arsenic (As)-treated rats $(\mathrm{P}<0.01)$. GSE, grape seed extract; IL, interleukin; TNF- $\alpha$, tumor necrosis factor- $\alpha$.

Table V. Levels of oxidative damage in the rat kidneys in different treatment groups.

\begin{tabular}{lccrr}
\hline Oxidative stress marker & Control group & GSE group & As group & GSE + As group \\
\hline ROS (pmol/mg protein) & $4.5 \pm 0.99$ & $4.3 \pm 1.02$ & $13.7 \pm 1.00^{\mathrm{a}}$ & $5.9 \pm 1.33^{\mathrm{b}}$ \\
TBARS (nmol/mg protein) & $0.33 \pm 0.07$ & $0.29 \pm 0.08$ & $0.71 \pm 0.09^{\mathrm{a}}$ & $0.46 \pm 0.07^{\mathrm{b}}$ \\
PCs (nmol/mg protein) & $1.66 \pm 0.36$ & $1.71 \pm 0.19$ & $4.50 \pm 0.45^{\mathrm{a}}$ & $2.20 \pm 0.33^{\mathrm{b}}$ \\
\hline
\end{tabular}

Results are presented as the mean \pm standard deviation $(\mathrm{n}=10)$. ${ }^{a}$ Values differ significantly from those of control rats $(\mathrm{P}<0.01)$; ${ }^{\mathrm{b}} \mathrm{values}$ differ significantly from those of arsenic (As)-treated rats $(\mathrm{P}<0.01)$. GSE, grape seed extract; ROS, reactive oxygen species; TBARS, thiobarbituric acid reactive substances; PCs, protein carbonyls.

body weights and greater kidney weights and ratios of kidney weight to body weight compared with the rats in the control group. Moreover, chronic As exposure increased BUN, Up and $\mathrm{P}_{\mathrm{Cr}}$ levels and decreased $\mathrm{C}_{\mathrm{Cr}}$, indicating that As treatment adversely affected renal function. These changes were significantly attenuated in the rats by cotreatment with GSE (Table III).

GSE attenuates the As-induced production of proinflammatory cytokines. Inflammation has been demonstrated to be important in the initiation of tubulointerstitial injury. To gain further insight into the mechanisms underlying the action of GSE, the expression levels of important proinflammatory cytokines known to be involved in the fibrotic process were studied. As shown in Table IV, the serum levels of IL-1 $\beta$, IL- 6 and TNF- $\alpha$ were significantly elevated in the rats in the As-treated group as compared with those in the control group $(\mathrm{P}<0.01)$. These effects, however, were suppressed by the simultaneous administration of GSE $(\mathrm{P}<0.01)$, suggesting that GSE ameliorated the As-induced hepatic inflammatory response (Table IV).

GSE alleviates As-induced oxidative damage. To examine whether GSE modified the ROS production caused by chronic As exposure, renal tissue ROS production was assessed using DCF-DA. In addition, the renal levels of lipid peroxidation were measured according to TBARS formation, while endogenous protein oxidation was measured according to the levels of PCs. The results revealed that chronic As exposure resulted in high levels of ROS, TBARS and PC production, whereas GSE treatment significantly ameliorated these changes in As-treated rats (Table V).

GSE attenuates As-stimulated mRNA expression of fibrogenic genes. It has been shown that chronic As exposure induces

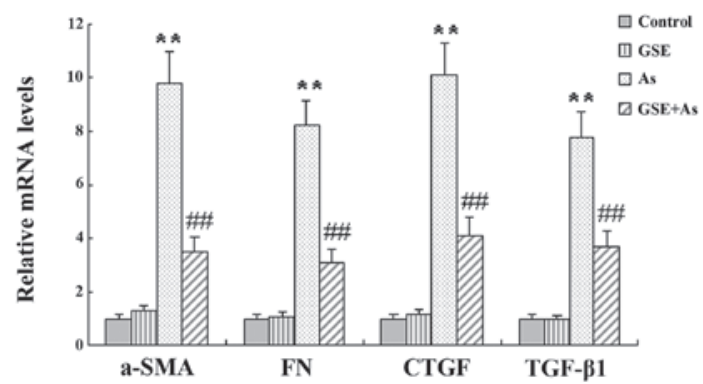

Figure 1. Effects of grape seed extract (GSE) on the arsenic (As)-induced intrahepatic mRNA levels of profibrogenic genes [ $\alpha$-smooth muscle actin $(\alpha-\mathrm{SMA})$, transforming growth factor- $\beta 1$ (TGF- $\beta 1$ ), connective tissue growth factor (CTGF) and fibronectin (FN)] were analyzed using quantitative polymerase chain reaction (qPCR) in rat livers. The mRNA levels of the control rats were arbitrarily set to 1 and all other values were calculated as multiples thereof. The transcript levels were corrected for $\beta$-actin levels. Results are presented as the mean \pm standard deviation $(\mathrm{n}=10)$. ${ }^{* *} \mathrm{P}<0.01$ compared with control rats; ${ }^{\# \#} \mathrm{P}<0.01$ compared with As-treated rats.

renal fibrosis. In the present study, this was corroborated by the quantification of the mRNA levels of various profibrogenic genes, specifically, $\alpha$-smooth muscle actin ( $\alpha$-SMA), TGF- $\beta 1$, connective tissue growth factor (CTGF) and fibronectin (FN). However, GSE cotreatment significantly attenuated the changes in the profibrogenic gene mRNA levels in the As-treated rat liver tissues (Fig. 1).

GSE inhibits As-induced Nox. It has been demonstrated that NADPH-derived ROS generation is pivotal in the progression of renal fibrosis. Therefore, in the present study, Nox activity and the protein expression levels of the NADPH subunits were assessed in kidney tissues, and the effects of GSE cotreatment on these variables were studied. The Nox activity and protein 


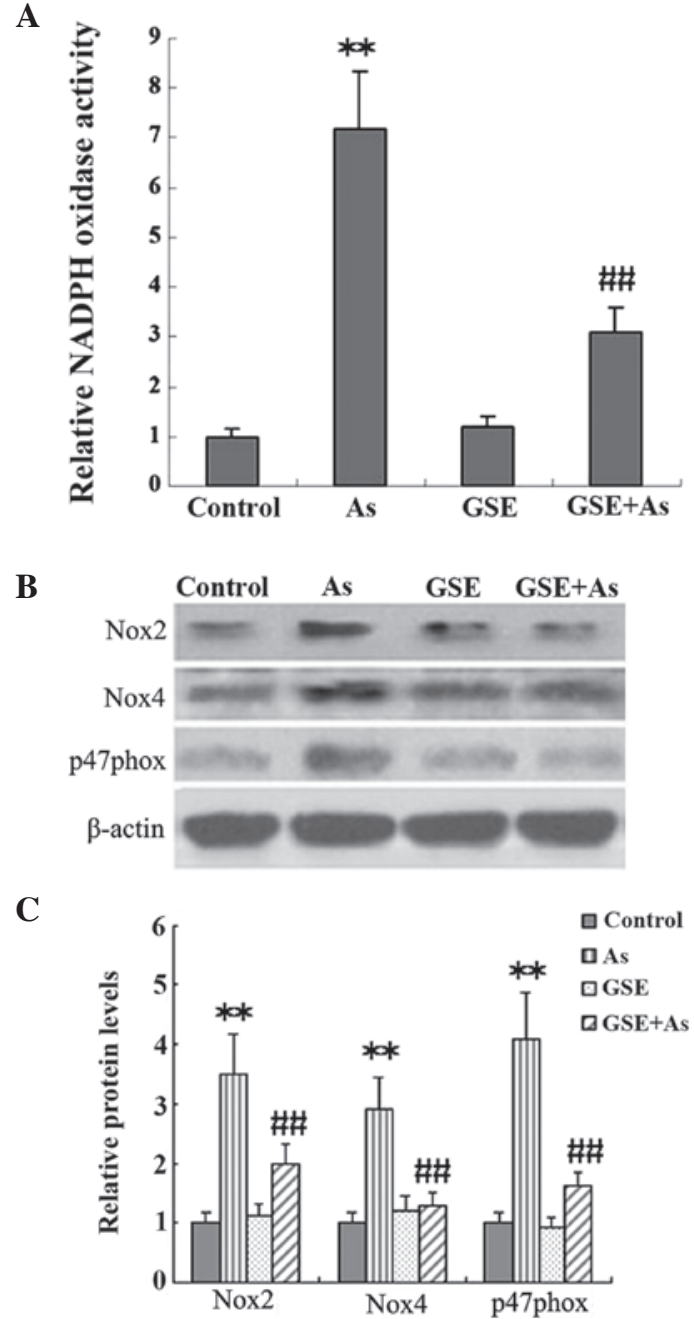

Figure 2. Grape seed extract (GSE) inhibits arsenic (As)-induced nicotinamide adenine dinucleotide phosphate (NADPH) oxidase (Nox). (A) Nox activity in isolated plasma membrane fractions of fresh kidney tissue homogenates was measured using chemiluminescence. Data are presented as the fold change relative to the control taken as $1.0 .{ }^{* *} \mathrm{P}<0.01$ compared with control rats; \#\# $\mathrm{P}<0.01$ compared with As-treated rats. (B) Renal tissue was homogenized and total proteins extracted, as detailed in Materials and methods. The protein levels of NADPH subunits (Nox2, p47phox and Nox4) were analyzed using western blotting. (C) Western blotting signals were quantified using densitometry and expressed in barograms as the mean \pm standard deviation $(n=10)$. Data normalized to the internal standard, $\beta$-actin, are presented as the fold change relative to the control taken as 1.0. ${ }^{* *} \mathrm{P}<0.01$ compared with control rats; ${ }^{\# \# ~} \mathrm{P}<0.01$ compared with As-treated rats.

expression levels of the NADPH subunits, Nox2, p47phox and Nox4, were significantly elevated in the As-treated rats as compared with the controls, and these increases were significantly alleviated by GSE cotreatment (Fig. 2).

GSE decreases As-induced TGF- $\beta 1 /$ Smad signaling. TGF- $\beta$ is an important signal transduction pathway mediator for renal fibrogenesis, which mediates its profibrotic effects by activating receptor-associated Smads ( $\operatorname{Smad} 2$ and $\operatorname{Smad} 3)$. In the present study, the protein levels of TGF- $\beta 1$ and $\mathrm{pSmad} 2 / 3$ were examined in renal tissues. As demonstrated using western blotting, chronic As-administration caused marked increases in the expression of TGF- $\beta 1$ and $\mathrm{pSmad} 2 / 3$ when compared with the expression levels in the control rats; however, cotreatment with GSE attenuated these changes (Fig. 3).

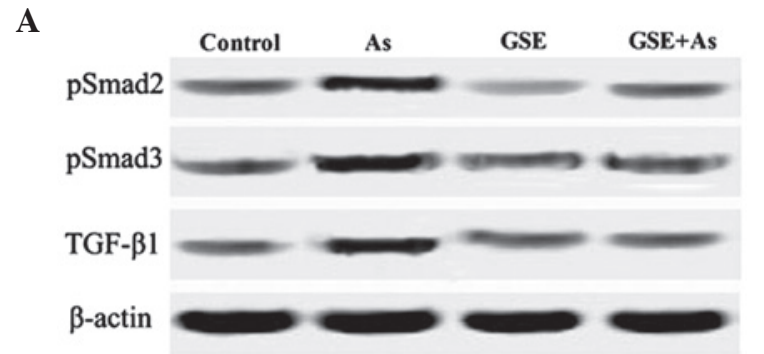

B

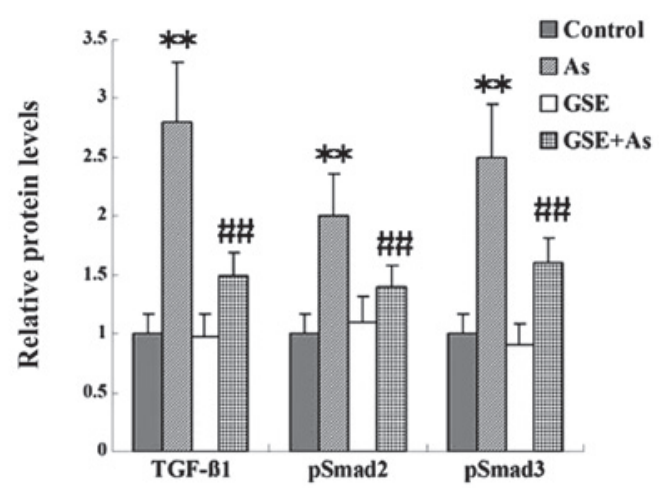

Figure 3. Grape seed extract (GSE) decreases arsenic (As)-induced transforming growth factor- $\beta 1$ (TGF- $\beta 1$ )/Smad signaling. Protein levels of TGF- $\beta 1$ and phosphorylated $\mathrm{Smad} 2 / 3(\mathrm{pSmad} / 3)$ in renal tissues were evaluated using western blot analysis. (A) A total of $60 \mu \mathrm{g}$ kidney tissue lysates were used in each SDS-PAGE lane. (B) Western blotting signals were quantified using densitometry and expressed in barograms as the mean \pm standard deviation $(n=10)$. Data normalized to the internal standard, $\beta$-actin, are presented as the fold change relative to control taken as 1.0 . ${ }^{* *} \mathrm{P}<0.01$ compared with the control rats; ${ }^{\#} \mathrm{P}<0.01$ compared with As-treated rats.

\section{Discussion}

In the present study, chronic As exposure was demonstrated to lead to renal dysfunction, as demonstrated by the increased BUN and $\mathrm{P}_{\mathrm{Cr}}$ and decreased $\mathrm{C}_{\mathrm{Cr}}$ levels (Table III). There is a common consensus that ROS and proinflammatory and profibrogenic cytokines, which result in oxidative damage, are important in the progression of fibrosis (23). Thus, it was plausible to hypothesize that the supplementation of an antioxidant during As treatment was likely to reduce As-induced renal fibrosis (24). GSE, which is rich in catechin, epicatechin and procyanidin, possesses greater antioxidant activity than vitamins $\mathrm{C}$ and $\mathrm{E}$, as well as $\beta$-carotene (15), and is considered to be a safe and effective antioxidant compound. The antioxidant and anti-inflammatory capacity of GSE has been previously demonstrated in other tissues $(25,26)$. The present study has, for the first time, to the best of our knowledge, demonstrated the protective effect of GSE against nephrotoxicity in rats following chronic As exposure at a low concentration. It was shown that cotreatment with GSE significantly improved renal function, attenuated As-induced serum levels of proinflammatory cytokines and prevented kidney fibrosis. Moreover, GSE treatment was capable of reducing As-stimulated NADPH-derived ROS generation. In addition, it was revealed that GSE cotreatment led to a significant reduction in TGF- $\beta /$ Smad signaling.

In the present study, a significant increase in the level of ROS production in the As treatment group indicated that oxidative damage was implicated in the nephrotoxicity caused 
by As (Table V). Exposure to As has been shown to lead to the increased generation of ROS (27-29). Furthermore, out of numerous pathways, Nox has been suggested to be the major source of ROS generation $(30,31)$, as demonstrated by the increased Nox activity and protein levels of NADPH subunits, Nox2, p47phox and Nox4, in the present study. However, cotreatment with GSE led to a pronounced recovery in the As-induced oxidative injury (Fig. 2). These results were indicative of the antioxidant effect of GSE.

Chronic As exposure resulted in oxidative stress in the renal tissues. Oxidative stress may have caused further lipid peroxidation (Table V), directly damaging the membranes of cells and organelles and leading to the release of reactive aldehydes with potent proinflammatory (Table IV) and profibrotic (Fig. 1) properties. This, in turn, may have promoted oxidative stress. TGF- $\beta 1$, as the most potent profibrogenic cytokine, is responsible for matrix synthesis by mesenchymal cells, such as fibroblasts, in vitro and during renal fibrosis $(32,33)$. TGF- $\beta 1$ accelerates renal fibrosis by a number of mechanisms. TGF- $\beta 1$ stimulates fibroblasts to convert into myofibroblasts, increases the expression of $\alpha$-SMA and FN and increases the synthesis of ECM components (34). Furthermore, TGF- $\beta 1$ inhibits the activity of a variety of ECM-degrading enzymes, such as matrix metalloproteinases (MMPs) and plasminogen activator, thereby inhibiting the degradation of the ECM. In addition, TGF- $\beta 1$ may stimulate tubular epithelial myofibroblast transdifferentiation $(35,36)$. The TGF- $\beta$ signaling pathway is regulated predominantly by Smads. TGF- $\beta$ binds to a receptor on the cell surface, forming a complex of subunits known as transforming growth factor- $\beta$ receptor 1 (TGFR1) and TGFR2. TGFR1 and TGFR2 activate serine/threonine kinases that subsequently mediate signaling through the Smad family of transcriptional activators $(37,38)$. It has been demonstrated that $\mathrm{Smad} 2 / 3$ is phosphorylated by activated TGFR1 and inhibited by Smad7. Moreover, Smad7 is capable of increasing the ubiquitin-mediated degradation of TGFR1 itself, thus preventing TGF- $\beta$ signal transduction. The results of the present study indicated that the As-induced rat renal injury was correlated with TGF- $\beta 1$-induced fibrosis, as demonstrated by the increased levels of TGF- $\beta 1$ and $\mathrm{pSmad} 2 / 3$ in renal tissue. GSE cotreatment attenuated these changes (Fig. 3).

Based on the results of the present study, it is hypothesized that the enhanced production of ROS and proinflammatory and profibrogenic cytokines may have been the possible mechanisms underlying the As-induced oxidative stress, which was critical in the development and progression of renal fibrosis. In addition, the results demonstrate that the activation of TGF- $\beta /$ Smad signaling was correlated with As-induced renal fibrosis, and that the suppression of TGF- $\beta / \mathrm{Smad}$ activation was involved in the beneficial effects of GSE. In conclusion, GSE, a powerful antioxidant with diverse beneficial effects, may be a promising agent for the prevention of renal fibrosis and dysfunction caused by chronic As exposure at a low concentration in drinking water.

\section{Acknowledgements}

This study was supported by the National Natural Science Foundation of China (grant nos. 30500540 and 81170630) and the Program for New Century Excellent Talents in University (grant no. NCET-09-0123).

\section{References}

1. Bao L and Shi H: Potential molecular mechanisms for combined toxicity of arsenic and alcohol. J Inorg Biochem 104: 1229-1233, 2010.

2. Eom SY, Lee YC, Yim DH, Lee CH, Kim YD, Choi BS, Park CH, Yu SD, Kim DS, Park JD and Kim H: Effects of low-level arsenic exposure on urinary $\mathrm{N}$-acetyl- $\beta$-D-glucosaminidase activity. Hum Exp Toxicol 30: 1885-1891, 2011.

3. Chen JW, Chen HY, Li WF, Liou SH, Chen CJ, Wu JH and Wang SL: The association between total urinary arsenic concentration and renal dysfunction in a community-based population from central Taiwan. Chemosphere 84: 17-24, 2011.

4. Chen Y, Parvez F, Liu M, et al: Association between arsenic exposure from drinking water and proteinuria: results from the Health Effects of Arsenic Longitudinal Study. Int J Epidemiol 40: 828-835, 2011.

5. Kitchin KT: Recent advances in arsenic carcinogenesis: modes of action, animal model systems, and methylated arsenic metabolites. Toxicol Appl Pharmacol 172: 249-261, 2001.

6. Jomova K, Jenisova Z, Feszterova M, Baros S, Liska J, Hudecova D, Rhodes CJ and Valko M: Arsenic: toxicity, oxidative stress and human disease. J Appl Toxicol 31: 95-107, 2011.

7. Kitchin KT and Ahmad S: Oxidative stress as a possible mode of action for arsenic carcinogenesis. Toxicol Lett 137: 3-13, 2003.

8. Kitchin KT and Conolly R: Arsenic-induced carcinogenesis - oxidative stress as a possible mode of action and future research needs for more biologically based risk assessment. Chem Res Toxicol 23: 327-335, 2010.

9. Brunati AM, Pagano MA, Bindoli A and Rigobello MP: Thiol redox systems and protein kinases in hepatic stellate cell regulatory processes. Free Radic Res 44: 363-378, 2010.

10. Samarakoon R, Overstreet JM, Higgins SP and Higgins PJ: $\mathrm{TGF}-\beta 1 \rightarrow$ SMAD/p53/USF2 $\rightarrow$ PAI- 1 transcriptional axis in ureteral obstruction-induced renal fibrosis. Cell Tissue Res 347: 117-128, 2012.

11. Liu Y: Renal fibrosis: new insights into the pathogenesis and therapeutics. Kidney Int 69: 213-217, 2006.

12. Liu Y: New insights into epithelial-mesenchymal transition in kidney fibrosis. J Am Soc Nephrol 21: 212-222, 2010.

13. Derynck $R$ and Zhang YE: Smad-dependent and Smad-independent pathways in TGF-beta family signalling. Nature 425: 577-584, 2003.

14. Iwano $M$ and Neilson EG: Mechanisms of tubulointerstitial fibrosis. Curr Opin Nephrol Hypertens 13: 279-284, 2004.

15. Bagchi D, Bagchi M, Stohs SJ, Das DK, Ray SD, Kuszynski CA, Joshi SS and Pruess HG: Free radicals and grape seed proanthocyanidin extract: importance in human health and disease prevention. Toxicology 148: 187-197, 2000.

16. Li WG, Zhang XY, Wu YJ and Tian X: Anti-inflammatory effect and mechanism of proanthocyanidins from grape seeds. Acta Pharmacol Sin 22: 1117-1120, 2001.

17. Kris-Etherton PM, Lefevre M, Beecher GR, Gross MD, Keen CL and Etherton TD: Bioactive compounds in nutrition and health-research methodologies for establishing biological function: the antioxidant and anti-inflammatory effects of flavonoids on atherosclerosis. Annu Rev Nutr 24: 511-538, 2004.

18. Pan X, Dai Y, Li X, Niu N, Li W, Liu F, Zhao Y and Yu Z: Inhibition of arsenic induced-rat liver injury by grape seed exact through suppression of NADPH oxidase and TGF- $\beta /$ Smad activation. Toxicol Appl Pharmacol 254: 323-331, 2011.

19. Morris EM, Whaley-Connell AT, Thyfault JP, Britton SL, Koch LG, Wei Y, Ibdah JA and Sowers JR: Low aerobic capacity and high fat diet contributes to oxidative stress and IRS-1 degradation in the kidney. Am J Nephrol 30: 112-119, 2008.

20. Hu R, Wang YL, Edderkaoui M, Lugea A, Apte MV and Pandol SJ: Ethanol augments PDGF-induced NADPH oxidase activity and proliferation in rat pancreatic stellate cells. Pancreatology 7: 332-340, 2007.

21. Draper HH and Hadley M: Malondialdehyde determination as index of lipid peroxidation. Methods Enzymol 186: 421-431, 1990.

22. Levine RL, Garland D, Oliver CN, Amici A, Climent I, Lenz AG, Ahn BW, Shaltiel S and Stadtman ER: Determination of carbonyl content in oxidatively modified proteins. Methods Enzymol 186: 464-478, 1990. 
23. Barnes JL and Gorin Y: Myofibroblast differentiation during fibrosis: role of NAD(P)H oxidases. Kidney Int 79: 944-956, 2011.

24. Flora SJ, Chouhan S, Kannan GM, Mittal M and Swarnkar H: Combined administration of taurine and monoisoamyl DMSA protects arsenic induced oxidative injury in rats. Oxid Med Cell Longev 1: 39-45, 2008.

25. Dulundu E, Ozel Y, Topaloglu U, Toklu H, Ercan F, Gedik N and Sener G: Grape seed extract reduces oxidative stress and fibrosis in experimental biliary obstruction. J Gastroenterol Hepatol 22: 885-892, 2007.

26. Terra X, Montagut G, Bustos M, Llopiz N, Ardèvol A, Bladé C, Fernández-Larrea J, Pujadas G, Salvadó J, Arola L and Blay M: Grape-seed procyanidins prevent low-grade inflammation by modulating cytokine expression in rats fed a high-fat diet. J Nutr Biochem 20: 210-218, 2009.

27. Mishra D and Flora SJ: Differential oxidative stress and DNA damage in rat brain regions and blood following chronic arsenic exposure. Toxicol Ind Health 24: 247-256, 2008.

28. Bhadauria S and Flora SJ: Response of arsenic-induced oxidative stress, DNA damage and metal imbalance to combined administration of DMSA and monoisoamyl-DMSA during chronic arsenic poisoning in rats. Cell Biol Toxicol 23: 91-104, 2007.

29. Nandi D, Patra RC and Swarup D: Oxidative stress indices and plasma biochemical parameters during oral exposure to arsenic in rats. Food Chem Toxicol 44: 1579-1584, 2006.

30. Suzuki S, Arnold LL, Pennington KL, Kakiuchi-Kiyota S and Cohen SM: Effects of co-administration of dietary sodium arsenite and an NADPH oxidase inhibitor on the rat bladder epithelium. Toxicology 261: 41-46, 2009.
31. Straub AC, Clark KA, Ross MA, Chandra AG, Li S, Gao X, Pagano PJ, Stolz DB and Barchowsky A: Arsenic-stimulated liver sinusoidal capillarization in mice requires NADPH oxidase-generated superoxide. J Clin Invest 118: 3980-3989, 2008.

32. Okuda S, Languino LR, Ruoslahti E and Border WA: Elevated expression of transforming growth factor-beta and proteoglycan production in experimental glomerulonephritis: Possible role in expansion of the mesangial extracellular matrix. J Clin Invest 86: 453-462, 1990.

33. Gaedeke J, Peters H, Noble NA and Border WA: Angiotensin II, TGF-beta, and renal fibrosis. Contrib Nephrol 135: 153-160, 2001.

34. Bondi CD, Manickam N, Lee DY, Block K, Gorin Y, Abboud HE and Barnes JL: NAD(P)H oxidase mediates TGF-beta1-induced activation of kidney myofibroblasts. J Am Soc Nephrol 21: 93-102, 2010.

35. Okada H, Danoff TM, Kalluri R and Neilson EG: Early role of Fsp1 in epithelial-mesenchymal transformation. Am J Physiol 273: F563-F574, 1997.

36. Fan JM, Ng YY, Hill PA, Nikolic-Paterson DJ, Mu W, Atkins RC and Lan HY: Transforming growth factor beta regulates tubular epithelial-myofibroblast transdifferentiation in vitro. Kidney Int 56: 455-1467, 1999.

37. Attisano L and Wrana JL: Signal transduction by the TGF-beta superfamily. Science 296: 1646-1647, 2002

38. Schnaper HW, Hayashida T and Poncelet AC: It's a Smad world: Regulation of TGF-beta signaling in the kidney. J Am Soc Nephrol 13: 1126-1128, 2002. 